\title{
Thermal Plasma Synthesis of Ceramic Nanomaterials
}

\author{
Received July 17, 2020; accepted August 26, 2020
}

Tae-Hee Kim ${ }^{\text {a }}$, Jeong-Hwan $\mathbf{O h}^{\mathbf{b}}$, Minseok Kim ${ }^{\mathbf{b}}$, Seung-Hyun Hong ${ }^{\text {b }}$, and Sooseok Choi ${ }^{\text {b,* }}$
aDepartment of Chemical Engineering, Wonkwang University, Iksan 54538, Republic of Korea
${ }^{b}$ Department of Nuclear and Energy Engineering, Jeju National University, Jeju 63243, Republic of Korea

*Corresponding author E-mail: sooseok@jejunu.ac.kr

\begin{abstract}
Many studies have been conducted on thermal plasma synthesis of ceramic nanomaterials by direct current and radio frequency thermal plasma. Furthermore, numerous researchers have attempted to develop processes to commercialize the thermal plasma process for practical applications. These processes can continuously fabricate beneficial high-value ceramic nanomaterials in a high enthalpy environment. In this review, several thermal plasma synthetic processes are described for different plasma sources and precursor types. Current understanding of the formation process of nanomaterials is also explained. In addition, the research trend for ceramic nanomaterials produced by thermal plasma is described and the limitations and challenges are also discussed.
\end{abstract}

Keywords: Thermal plasma, Synthesis, Nanomaterial, Ceramic, Nanoparticles

\section{Introduction}

Thermal plasma processing can be accomplished using atmospheric arcs, sparks, or flames. It was first used in practical industrial applications at the beginning of the $20^{\text {th }}$ century. Marconi used an electric arc for radio transmission across the Atlantic in 1901. In southern Norway, 120 arc furnaces of the Schoenherr and BirkelandEyde design were installed around 1910 for nitrogen fixation. In this electric arc process, proposed by Birkeland and Eyde in 1903, nitrogen and oxygen in the air were combined to form nitrogen oxide and nitric acid for use as artificial fertilizer (Norway nitre, calcium nitrate, $\left.\mathrm{Ca}\left(\mathrm{NO}_{3}\right)_{2} \cdot(2.5 \sim 4) \mathrm{H}_{2} \mathrm{O}\right)$. Arc welding was first established around 1910 and is now used for most fusion welds. In 1909, Schoenherr was the first to use a forced gas flow to stabilize long carbon arcs. Various kinds of arc stabilization techniques were developed for plasma torches. The fundamentals and applications of thermal plasmas are discussed in a book edited by Boulos et al. [1]. In the $20^{\text {th }}$ century, the most popular plasma applications were for fluorescent light, plasma spraying, welding and cutting, metallurgical processing, and waste disposal [2-4].

Since the late 1990s, the applications for thermal plasma in materials processing industries has become an increasingly active and attractive field for the development of new technology [5]. In the industrial field, the demand for nanomaterials is increasing to reduce the size of electronic devices [6-8]. Thermal plasma is a promising dry production method. The potential applications of thermal plasma technology cover a wide range of activities for nanomaterial processing, understanding, and development. Several studies have been conducted to produce different functional metal, ceramic, and composite nanomaterials [4,9-12]. Thermal plasma facilitates chemical or physical reactions of solid, liquid, or gaseous phase precursors [13-15].

The generated plasma arc channel or plasma medium rapidly expands at the torch nozzle as the compressed gas flows, and it generates extremely high temperatures up to $20,000 \mathrm{~K}$. In addition, it generates high velocity due to gas expansion, from a few hundred $\mathrm{m} / \mathrm{s}$ to supersonic speeds depending on the torch design. Most thermal plasmas approach the state of local thermodynamic equilibrium and need to generate high temperatures to maintain sufficient electrical conductivity by thermal ionization. The input power used is generally in the range of a few tens of $\mathrm{kW}$. Thermal plasma has excellent features enabling it to produce nanomaterials. These include a high enthalpy medium with high temperatures to evaporate precursors, a rapid temperature gradient to create condensate at nanoscale levels, and high heat contents. It enables chemical synthesis reactions and physical reactions for metal, ceramic, and composite nanomaterials. The main advantages of thermal plasma synthesis of nanomaterials are:

- High energy density in a small volume of plasma

- High rate of chemical reaction for high productivity

- The stationary heating of gas to the mean temperature up to $20,000 \mathrm{~K}$

- The heating of almost all gases: for reduction, oxidation, inert gases, and mixtures

- No limitation of precursors: solid, liquid, or gas precursors

- Solvent-free dry processing

In addition, the characteristics of manufactured nanomaterials such as morphology, crystallinity, crystal phase and size can be controlled through the generation conditions of the plasma or processing variables [16-19]. Recently, there have been many efforts to implement mass production of nanomaterials using the thermal plasma process $[20,21]$.

Thermal plasma is generated by various discharge sources (such as direct current (DC), alternating current, radio frequency (RF), or microwave). Among them, the most used thermal plasma generation sources in the nanomaterial process are DC and RF. DC thermal plasma is categorized as both the non-transferred and transferred arc 
types. A schematic diagram of individual torches is shown in a previous study [22]. A DC torch typically consists of a rod-type cathode and an anode nozzle and is classified into non-transferred or transferred-type depending on the arrangement of anode electrodes. The cathode is generally made of thoriated tungsten and the anode is normally copper. In the non-transferred type torch, the arc channel is generated inside the torch between the cathode and the anode by applying a high voltage. The expanded plasma jet or flame is used to produce nanomaterials. In the transferred type torch, the arc is applied to the vaporization of the precursor, The target material (i.e., precursor) should be the anode and the arc is generated between the cathode in the torch and the precursor. In some cases, the pilot anode electrode is located inside the torch to generate an initial arc. The plasma forming gas in DC torches is flown with the arc column and heated by joule and radiation heating. An RF plasma torch consists of a confinement tube and an electromagnetic coil as an electroless torch. RF thermal plasma is generated by induction heating. An oscillating current in the coil generates an alternating magnetic field inside the confinement tube. The heat energy by joule heating maintains continuous ionization of the injected gas, thus generating a plasma flame.

The features of individual torches are summarized in Table I for comparison purposes. DC plasma torches are easy to use to control the discharge environment while RF plasma discharge is very sensitive and with a relatively low stability because of the need for an impedance matching box. The thermal efficiency of DC plasma torches is higher than RF plasma torches. The system scale of DC thermal plasma is typically smaller compared with RF plasma systems, because RF plasma torches are bigger and require impedance matching boxes and vacuum systems. In addition, a larger amount of plasma forming gases such as argon and nitrogen is needed in RF thermal plasma generation. Therefore, the operating cost for RF plasma systems is relatively high. However, RF torches are free from product contamination by electrode erosion since RF torches do not have metallic electrodes. This is advantageous during production of high-purity nanomaterials such as silicon nanoparticles for semiconductor fabrication. In DC torches, the metallic electrodes are eroded by the arc root attachments and the partially melted or evaporated electrodes occasionally affect the product purity. In addition, as the electrode gets consumed through electrode erosion, the shorter life of the electrode increases the operating cost. However, this can be controlled by adjusting the arc rotation stability. Oxidative plasma forming gas should be avoided for DC plasma discharge because the formation of an oxide layer on the anode surface reduces the thermal and electric conductivity. However, the oxygen-containing gas is used as a plasma forming gas in RF thermal plasma. On the other hand, several inert and reductive gases are used in DC torches such as $\mathrm{Ar}, \mathrm{N}_{2}, \mathrm{H}_{2}, \mathrm{He}$, or mixed gases. RF torches can generate Ar-based plasma and the gas switching is sensitive to sustaining the plasma discharge. DC non-transferred arc types and RF thermal plasmas are not limited by the precursor, but the precursor or raw material should be an electrically conductive material to create an arc channel because the precursor is the anode electrode. In addition, hybrid-type torches have been developed to overcome the individual limitations, for example, RF-DC thermal plasma and multiple torch systems [23-26].

\section{Principle of thermal plasma synthesis}

The thermal plasma synthesis of nanomaterials is mainly applied using the bottom-up approach. It corresponds to the nanomaterial synthesis in the DC non-transferred and RF thermal plasma process [27]. The precursor or raw material is injected into the high temperature plasma flame (several thousand Kelvin) and vaporized immediately. The vapor is transported to the tail or rim of the plasma flame and quenched where the temperature rapidly decreases because of the thermal expansion with the high velocity flow. The vapor is supersaturated by the rapid quenching $\left(10^{4} \sim 10^{6} \mathrm{~K} / \mathrm{s}\right)$, which causes homogeneous nucleation. The numerous nuclei continuously grow by heterogeneous condensation and coagulation until the solidification temperature is reached.

In multi-component systems, the chemical reactions occur from the reactive gas, ion, or radical species produced by the thermal plasma. Single component systems are used to produce metallic or non-metallic nanomaterials through size reduction and refinement. Multi-component systems are used to synthesize ceramic or composite nanomaterials from a multi-component precursor or additional reactive gas.

Nanomaterials are usually collected from the inner wall of

Table I. Comparison according to the generation method of thermal plasma.

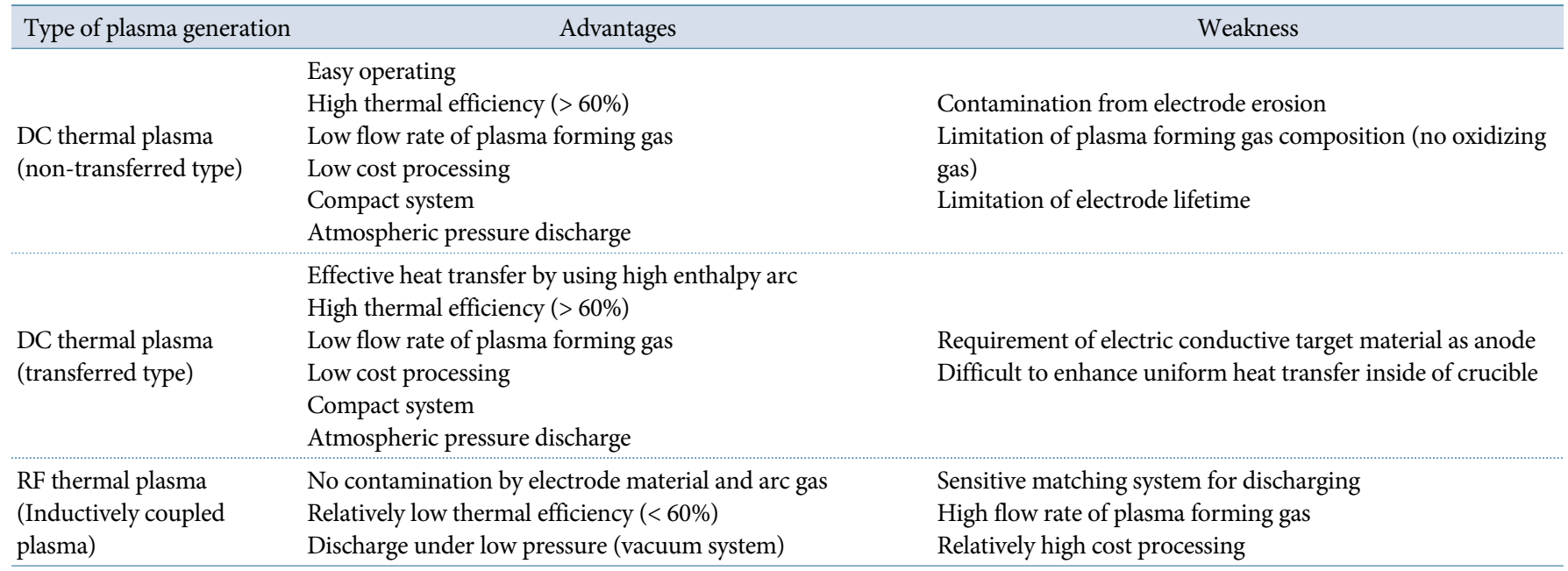


reactors or backward filters. In the DC transferred arc plasma process, the arc root attaches to the surface of raw material inside the crucible and the high enthalpy of the arc melts and evaporates the target material. The generated vapor is transported to the outside of the plasma jet and undergoes the process described above.

For these formation processes, the processing parameters have an influence on the chemical and physical properties of produced nanomaterials. These parameters include flow rate, composition of plasma forming gas, input power, feeding rate of precursor, additional quenching gas, and reactor design. A different thermal environment such as the thermal distribution, vapor density, or growth time of nanoparticles transforms the nanoparticle formation process. Thermal distribution depends on the plasma discharging conditions such as composition and flow rate of plasma forming gas, pressure, torch design, and input power. The vapor density is affected by the feeding rate of precursors. The growth time determines the crystallinity, crystalline phase, morphology, and size of produced nanomaterials. A narrow, additional quenching gas is often introduced into the plasma flame to control size distribution. The growth of nanoparticles ends before they become micron particles. During this process, nonequilibrium thermodynamics or metastable crystal phases might be produced by the rapid quenching. The size of the nanomaterial obtained is generally distributed from several nanometers to hundreds of nanometers, although it depends on the specific experimental conditions.

\section{Synthesis of ceramic nanomaterials}

\subsection{Oxide nanomaterials}

Metal oxides are typically synthesized through exothermic oxidation reactions. The change in Gibbs free energy $(\triangle G)$ of the oxidation reaction increases with increasing temperature [22]. High temperature environments like thermal plasma may not be favorable for the formation of oxides because of Le Châtelier's principle. Therefore, the in-flight thermal oxidation by thermal plasma has focused on mass production using the advantages of thermal plasma, such as rapid thermal flow and condensation, to control crystalline phase and size.

For instance, titanium dioxide $\left(\mathrm{TiO}_{2}\right)$ nanoparticles have been synthesized by controlling the crystalline phase of anatase and rutile by DC non-transferred arc or RF thermal plasma [18,28-30]. $\mathrm{TiO}_{2}$ nanopowder is typically produced as a mixture of anatase and rutile phases. For many applications, they should be separated or individual phases should be increased, because the anatase and rutile phases have different physical and chemical properties. In an RF thermal plasma process $\left(2 \mathrm{MHz}, 25-40 \mathrm{~kW}, 53-80 \mathrm{kPa}, \mathrm{Ar} / \mathrm{O}, \mathrm{Ar} / \mathrm{He} / \mathrm{O}_{2}, \mathrm{Ar} / \mathrm{H}_{2} / \mathrm{CO}_{2}\right.$ plasmas), it was shown that the rapid cooling suppressed the supply of oxygen into the coagulated particles, promoting the formation of oxygen-deficient rutile. The anatase/rutile ratio is controlled to 20-75 wt. $\%$ by changing the oxygen content in the plasma gas and the thermal history of the $\mathrm{TiO}_{2}$ during the nucleation and the subsequent growth [29]. The reduced concentration of oxygen atoms in the gas phase promoted the preferred formation of rutile by the oxygendeficient nature of the rutile phase. The faster cooling suppressed the supply of oxygen into the coagulated particles, promoting the formation of oxygen-deficient rutile. In addition, in order to control the cooling rate, several modes of quenching gas injection (radial, counter, and swirl injections) have been studied with different cooling gases (Ar or He) [29]. Kim et al. carried out a thermal oxidation experiment using titanium tetrachloride $\left(\mathrm{TiCl}_{4}\right)$ with a DC nontransferred arc plasma (9-15 kW, $101 \mathrm{kPa}, \mathrm{Ar} / \mathrm{N}_{2}$ plasma) [18]. The thermal history (temperature gradient) of the nucleated $\mathrm{TiO}_{2}$ was controlled with and without a graphite insulation tube [18]. As a result, the anatase-rich and rutile-rich powder were individually synthesized at 95 and $96 \%$, respectively.

Furthermore, with a growing demand for renewable energy, impurity doping technology of $\mathrm{TiO}_{2}$ has been developed using a DC non-transferred arc plasma. For improved photocatalytic performance, $\mathrm{TiO}_{2}$ was doped by various dopants such as carbon, aluminum, and copper [31-34]. The photocatalytic activity in the ultraviolet region was extended to the visible region after doping. The degree of doping was readily controllable by adjusting the concentration of dopants in the precursors. The oxide nanomaterials have been generally fabricated as composite materials in the thermal plasma process.

\subsection{Nitride nanomaterials}

Generally, nitride materials have excellent hardness, wear resistance, corrosion resistance, and high thermal conductivity. They can be used in various industrial applications such as refractory ceramics, and for catalysts, semiconductor devices for optoelectronics, and wear-resistant coatings. Many nitride materials are integrated as functional inorganic fillers to polymeric composites. Their performance can be tailored by adjusting the morphology and size of the filled inorganic particles (i.e., nitrides). Organic-inorganic composites often have high thermal conductivity, which can be used to dissipate heat in miniaturized integrated electronic components. Aluminum nitride $(\mathrm{AlN})$ and boron nitride (BN) are typical inorganic materials with high thermal conductivity. However, the improvement of thermal conductivity is limited since it is difficult to disperse homogeneously and to form efficient thermal conductive paths [35]. Nano-sized nitride particles can address these limitations. Moreover, high temperatures are needed for the nitridation of metals to be thermodynamically optimal [22].

Many metal nitride nanoparticles have been synthesized using $\mathrm{DC}$ and RF thermal plasma processes. Ammonia and nitrogen gas have been commonly used as nitridation agents. Although nitrogen is easy to use as a plasma forming gas, ammonia gas is highly reactive because of the $\mathrm{NH}$ radicals released by thermal decomposition. This is shown by the thermodynamic equilibrium composition depending on the nitridation agent and precursor [36]. From the aluminum vapor, nitridation is spontaneous from 2,700 K. Ammonia gas $\left(\mathrm{NH}_{3}\right)$ reduces that temperature to $2,600 \mathrm{~K}$, and completely synthesizes AlN at 2,350 $\mathrm{K}$. Using aluminum chloride $\left(\mathrm{AlCl}_{3}\right)$ as a precursor reduces the nitridation temperature to $500 \mathrm{~K}$; however, the chances of producing undesirable by-products is increased. Therefore, both the nitridation agent and the precursor should be carefully selected. Aluminum nitride was successfully synthesized from $\mathrm{Al}$ and $\mathrm{AlCl}_{3}$ powder and an Al lump using a DC thermal plasma (10-12 kW, $101 \mathrm{kPa}, \mathrm{Ar} / \mathrm{N}_{2}$ plasma) $[16,36]$. The flow rate of $\mathrm{NH}_{3}$ is an important parameter to determine the crystallinity, particle size, and vaporization quality of the precursor. The additional injection of $\mathrm{NH}_{3}$ generates recirculation flow within the plasma jet and improves particle size and crystallinity by enhanced heat transfer. An excessive $\mathrm{NH}_{3}$ flow, however, decreases the particle size and crystallinity as the growth time of AlN reduces at 
high temperatures.

Most metal nitride nanoparticles were synthesized with high crystallinity in the thermal plasma processes; however, synthesis of crystalline silicon nitride $\left(\alpha-\mathrm{Si}_{3} \mathrm{~N}_{4}\right)$ nanoparticles has been very challenging. Most reaction products were either heavily contaminated by silicon nanoparticle by-products $(2.45 \mathrm{GHz}$ microwave plasma, 1 $\mathrm{kW}, \mathrm{Ar} / \mathrm{N}_{2} / \mathrm{H}_{2}$ plasma, silicon tetrachloride $\left(\mathrm{SiCl}_{4}\right)$ precursor) or were less crystallized (DC, $10-11 \mathrm{~kW}$, Ar plasma, $\mathrm{SiCl}_{4} / \mathrm{NH}_{3} / \mathrm{H}_{2}$ precursors, $15-75 \mathrm{kPa}$ ) [37,38]. This was caused by exposure to temperatures above $1,850{ }^{\circ} \mathrm{C}$ when the silicon nitride was decomposed into silicon and nitrogen. In addition, in-situ annealing of the produced $\mathrm{Si}_{3} \mathrm{~N}_{4}$ to form an $\alpha-\mathrm{Si}_{3} \mathrm{~N}_{4}$ phase is challenging at low temperatures. $\alpha-\mathrm{Si}_{3} \mathrm{~N}_{4}$ was obtained either by annealing the produced amorphous $\mathrm{Si}_{3} \mathrm{~N}_{4}$ at 1,500 ${ }^{\circ} \mathrm{C}$ under a nitrogen atmosphere or through size reduction processing of micro-sized $\alpha-\mathrm{Si}_{3} \mathrm{~N}_{4}$ powders in an RF thermal plasma jet $(4 \mathrm{MHz}$, $10 \mathrm{~kW}$, Ar plasma, $\mathrm{SiCl}_{4} / \mathrm{NH}_{3}$ precursors) [35]. Gallium nitride nanoparticles have a similar issue [39]. Thermal pretreatment is needed to crystallize gallium nitride from amorphous gallium nitride.

$\mathrm{BN}$ is one of the most attractive materials because of its high thermal conductivity and low electrical conductivity. Hexagonal boron nitride ( $\mathrm{h}-\mathrm{BN}$ ) was synthesized as nanoparticles and nanotubes by $\mathrm{DC}\left(13 \mathrm{~kW}, 101 \mathrm{kPa}, \mathrm{Ar}, \mathrm{Ar} / \mathrm{N}_{2}\right.$ plasma) and $\mathrm{RF}$ thermal plasma (2-4 MHz, $50 \mathrm{~kW}, 93 \mathrm{kPa}, \mathrm{Ar} / \mathrm{H}_{2} / \mathrm{N}_{2}$ plasma), respectively [20,40-42]. Boron nitride nanotubes (BNNTs) have a similar structure to carbon nanotubes (CNTs), which are cylinders with sub-micrometer diameters and micrometer lengths, except that carbon atoms are alternately substituted by nitrogen and boron atoms. However, the properties of BNNTs are completely different. Whereas CNTs are metallic or semiconducting depending on the rolling direction and radius, BNNTs are strong electrical insulators with a bandgap of $\sim 5.5 \mathrm{eV}$, independent of the tube chirality and morphology [43]. In addition, a layered BN structure is much more thermally and chemically stable than a graphitic carbon structure [44-47]. BNNT paper exhibits the highest thermal stability without any morphological changes. It can be used as fiber for aerospace applications because of its strength and radiationshielding properties (e.g., from cosmic ray spallation neutrons). The addition of hydrogen as a reactant gas is an essential factor for achieving high-quality and high yield BNNTs. The high thermal conductive hydrogen enhances not only the vaporization of the precursor (BN) by improving the heat transfer, but also the formation of $\mathrm{NH}$ and $\mathrm{BH}$ radicals to form $\mathrm{BNH}$ bonding. It then shows the effect of hydrogen on the morphological properties of the $\mathrm{BN}$ reaction through the injection of hydrogen (24 vol.\%) into single-walled and multi-walled BNNTs. In the meantime, boron particles encapsulated with h-BN shells were produced without hydrogen. Furthermore, thermal plasma can be used for the mass production of BNNTs at 20 $\mathrm{g} / \mathrm{h}(0.36 \mathrm{~g} / \mathrm{h} \cdot \mathrm{L}$ for production rate per nitrogen gas). The advanced $\mathrm{RF}$ thermal plasma process has been used for the mass production of BNNTs at a pressure of $300 \mathrm{kPa}$. The boron powder was used as the precursor and BNNTs were continuously produced at $35 \mathrm{~g} / \mathrm{h}$ in the absence of hydrogen [48]. Recently, the highest production rate per nitrogen gas for BNNT synthesis was reported as $0.525 \mathrm{~g} / \mathrm{h} \cdot \mathrm{L}(12.6 \mathrm{~g} / \mathrm{h}$ for production rate) in our laboratory (Fig. 1) [49].

Cubic boron nitride $(\mathrm{c}-\mathrm{BN})$ is only synthesized artificially and is an unnatural crystalline structure. c-BN is used as an alternate material to diamond due to its exceptional hardness, thermal conductivity, and electrical resistivity. c-BN nanoparticles less than $150 \mathrm{~nm}$ were synthesized by a DC plasma jet $\left(13 \mathrm{~kW}, 101 \mathrm{kPa}, \mathrm{Ar} / \mathrm{N}_{2}\right.$
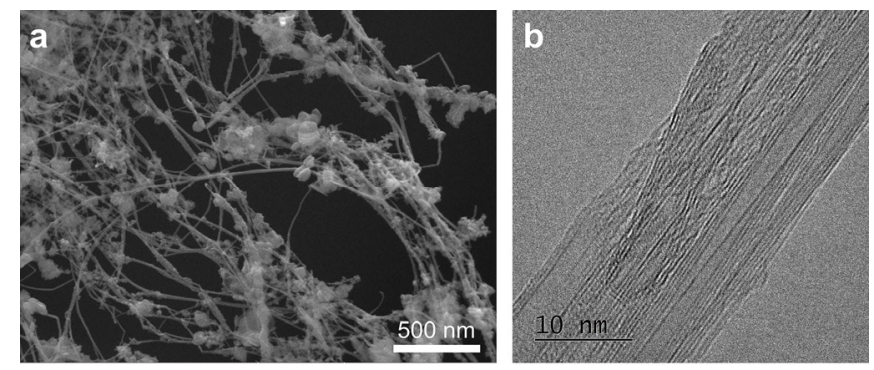

Figure 1. Synthesized boron nitride nanotubes formed using triple direct current thermal plasma system: (a) field emission scanning electron microscopy (FE-SEM), and (b) field emission transmission electron microscopy (FE-TEM) images.

plasma) using a mixture of boron oxide $\left(\mathrm{B}_{2} \mathrm{O}_{3}\right)$ and melamine $\left(\mathrm{C}_{3} \mathrm{H}_{6} \mathrm{~N}_{6}\right)$ as a precursor [50]. Melamine was used as a reductant to boron oxide, and the decomposed melamine generated various exothermic gases, such as $\mathrm{CO}, \mathrm{CO}_{2}, \mathrm{H}_{2}$, and $\mathrm{N}_{2}$. Although the growth mechanism of $\mathrm{c}-\mathrm{BN}$ nanoparticles in this plasma process is still not fully understood, it is believed that extremely high temperatures play an important role. The cost of BNNTs and c-BN is very high; however, the thermal plasma process has the potential to reduce the production cost by continuous fast processing.

In addition, magnesium nitride and titanium nitride nanoparticles have been successfully produced by thermal plasma [37,51-53].

\subsection{Carbide nanomaterials}

Metal carbide materials have been considered high-value products for use as refractory material because of their exceptional hardness, electrical and thermal conductivity, and high stability. Spherical tungsten carbide (WC) nanoparticles have been used as hardfacing surface coatings for various machine tools that need to withstand high thermal/mechanical stress, and also as high performance electric catalysts [22]. Silicon carbide ( $\mathrm{SiC}$ ) improves energy efficiency by reduced electric loss and is a most promising semiconducting material with high strength similar to that of a diamond and lower resistance than silicon,. Applying silicon carbide nanoparticles as a power semiconductor is beneficial for electric cars, solar cells, fuel cells, wind generators, and various other electronic devices. Thermal plasmas are frequently used for synthesizing metal carbides, because at high temperatures carbonized metals are highly effective thermodynamically. Although direct carbonization of silicon is possible at high plasma temperatures, $\mathrm{SiCl}_{4}$ is widely used as a precursor with carbon-including gas because of the high reactivity and easy production of silicon vapor.

Silicon carbide nanoparticles less than $100 \mathrm{~nm}$ have been synthesized from $\mathrm{SiCl}_{4}$ and methane gas using a DC non-transferred arc plasma jet (8-12 kW, $101 \mathrm{kPa}, \mathrm{Ar} / \mathrm{H}_{2}$ plasma) [54]. It was shown that the powder quality depended on the ratio of $\mathrm{H} / \mathrm{Si}$ and $\mathrm{C} / \mathrm{Si}$, and the position of the collecting points. It may be assumed that high thermal conductive hydrogen gas promoted the decomposition and reduction of the $\mathrm{SiCl}_{4}$. However, the excessive carbon suppressed the formation of crystalline $\mathrm{SiC}$, and resulted in solid carbon contamination. In the synthetic experiment, the optimum ratio of $\mathrm{H} / \mathrm{Si}$ and $\mathrm{C} / \mathrm{Si}$ were determined as 26 and 1.1 vol.\%, respectively. In addition, the crystallinity of synthesized $\mathrm{SiC}$ was better at the backward filter than at the forward reactor. This is explained by the fact that the 

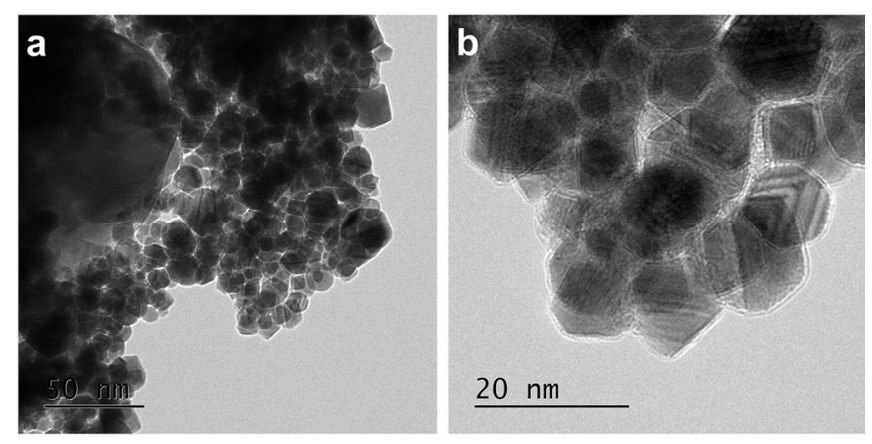

Figure 2. FE-TEM images of the tungsten carbide nanoparticles formed using triple direct current thermal plasma system.

synthesis of silicon carbide for in-flight crystallization improves with time at high temperatures.

The hardness of WC particles larger than $1 \mu \mathrm{m}$ increases linearly with their size while it increases exponentially for particles smaller than $100 \mathrm{~nm}$. The preparation of WC nanoparticles has been of particular interest during the $20^{\text {th }}$ century. In spite of numerous studies on particle-particle, particle-gas, and gas-gas reactions, the most important limitation has been the low purity [55-58]. Unlike other metal carbides prepared by thermal plasma, WC nanoparticles were synthesized from a mixture of several variants of tungsten compounds such as stable $\mathrm{WC}$, metastable $\mathrm{W}_{2} \mathrm{C}$, and metastable $\mathrm{WC}_{1-\mathrm{x}}$. Despite considerable efforts to optimize the parameters for a DC plasma process (11-32 kW, $101 \mathrm{kPa}$, Ar plasma) such as the molar ratio of reactant gases, input power, the flow rate of discharge gas, and the addition of $\mathrm{H}_{2}$, metastable $\mathrm{WC}_{1-\mathrm{x}}$ nanoparticles less than $20 \mathrm{~nm}$ always dominated when using tungsten hexachloride, $\mathrm{H}_{2}$, and methane $\left(\mathrm{CH}_{4}\right)$ precursors [55]. The synthesized $\mathrm{W}_{2} \mathrm{C}$ and $\mathrm{WC}_{1-\mathrm{x}}$ nanoparticles can be carburized completely to form a WC phase by post hydrogen treatment at $900{ }^{\circ} \mathrm{C}$ for 5 hours. However, the size of the final particles increased from $20 \mathrm{~nm}$ to $100 \mathrm{~nm}$ during the heat treatment.

Recently, the synthesis of tungsten carbide nanoparticles was carried out using several precursors with a triple DC thermal plasma system (27-30 kW, $101 \mathrm{kPa}, \mathrm{Ar} / \mathrm{N}_{2}$ plasma) [59]. Micron-sized tungsten refractory powder was successfully vaporized by introducing a precursor into the high temperature region of the merged plasma jet. High-purity precursor (i.e. pure metal compared with a compound precursor) can synthesize high-purity product as shown in Fig. $2 . \mathrm{W}_{2} \mathrm{C}$ and $\mathrm{WC}_{1-\mathrm{x}}$ are more predominantly crystalline structures than the $\mathrm{WC}$ in the above experiments. As the $\mathrm{W} / \mathrm{CH}_{4}$ composition ratio increased, the main crystal structure was changed from $\mathrm{W}_{2} \mathrm{C}$ to $\mathrm{WC}_{1-\mathrm{x}}$. It was understood that the $\mathrm{WC}_{1-\mathrm{x}}$ crystal phase is more stable at higher temperatures than $\mathrm{WC}$ and $\mathrm{W}_{2} \mathrm{C}$ since the high flow rate of $\mathrm{CH}_{4}$ can generate a carbon-rich and higher enthalpy environment. WC nanoparticles can be used in several manufacturing industries ranging from jewelry to weapons. The development of a one-step and phase-controlled thermal plasma synthesis process should therefore have an impact on the tungsten carbide market.

In addition, titanium carbide (TiC) and tantalum carbide (TaC) nanoparticles have been synthesized by DC and RF thermal plasmas, respectively [60,61]. Ishigaki et al. used tantalum ethoxide $\left(\mathrm{Ta}\left(\mathrm{OC}_{2} \mathrm{H}_{5}\right)_{5}\right)$ as a liquid precursor with $\mathrm{CO}_{2}$ carrier gas as the carbonization agent in RF thermal plasma ( $2 \mathrm{MHz}, 40 \mathrm{~kW}, 400-750$ Torr, $\mathrm{Ar} / \mathrm{H}_{2} / \mathrm{CO}_{2}$ plasma) [61]. The liquid precursor was injected in an atomized state because of the low heat transfer to the droplets. It was concluded that increasing the molar ratio of $\mathrm{H}_{2}$ to $\mathrm{Ta}\left(\mathrm{OC}_{2} \mathrm{H}_{5}\right)_{5}$ improved the $\mathrm{TaC}$ yield up to 97.4 wt.\%. Furthermore, the He gas injection had a significant effect on the size distribution of synthesized $\mathrm{TaC}$ nanoparticles. He is a much lighter gas than Ar gas, and therefore it does not influence the turbulence of the plasma flow. It did, however, cool down the plasma jet due to the high thermal conductivity, and the injection resulted in a very small size distribution of from 4 to $14 \mathrm{~nm}$ with an average size of $7.8 \mathrm{~nm}$. It is therefore effective at producing uniform sized nanoparticles.

\subsection{Boride nanomaterials}

There is a large group of metal borides with compositions that range from the most boron-rich yttrium boride $\left(\mathrm{YB}_{66}\right)$ (used as a monochromator for synchrotron radiation) to the most metal-rich neodymium magnet $\left(\mathrm{Nd}_{2} \mathrm{Fe}_{14} \mathrm{~B}\right)$ (considered as the best permanent magnet) [62]. Boron tends to form covalent molecular bonding, in spite of unusual molecular and extended structures, because of the formation of multicenter B-B bonds resulting from one less valence electron than the number of valence orbitals. Therefore, boron can theoretically react with most metals to form metal borides. Until now, more than 1,000 binary and ternary borides have been prepared and analyzed. It has been shown that over 150 types of boride structures are well crystallized [62]. Most borides have high melting points, excellent wear resistance, and a chemical inertness due to the strong covalent boron-boron and metal-boron bonds. Moreover, many boron-rich borides are very stable when exposed to neutron and other types of radiation. The borides have large neutron absorption cross-sections because of the presence of the element boron, and are therefore highly suited for use in the fabrication of mechanical parts exposed to extreme conditions such as high temperature or radiative environments.

The successful preparation of boride powder by thermal plasma was demonstrated in 1984 [63]. Baumgartner and Steiger synthesized titanium boride $\left(\mathrm{Ti}_{2} \mathrm{~B},<4 \mu \mathrm{m}\right)$ from $\mathrm{TiCl}_{4}$ and boron trichloride precursors, and sub-micron $\mathrm{Ti}_{2} \mathrm{~B}$ powders with an arc heater. They also conducted synthetic experiments of metal borides with DC and $\mathrm{RF}$ thermal plasma in the 2010s. Boridation reactions are most thermodynamically challenging with relatively high values of the Gibbs free energy compared with oxidation, nitridation, and carbonization [22]. In addition, to avoid contamination, pure boron and metal powders are suitable precursors. Therefore, thermal plasma synthesis is effective for synthesizing boride nanoparticles from a refractory boron precursor whose vaporization temperature is above $4,200 \mathrm{~K}$.

Various metal boride nanoparticles have been successfully synthesized by RF and DC thermal plasma in the Watanabe and Choi laboratories. In RF thermal plasma systems (4 MHz, $101 \mathrm{kPa}, 30 \mathrm{~kW})$, aluminum boride, $\mathrm{YB}_{66}$, titanium boride, iron boride, cobalt boride, niobium boride, and nickel boride were synthesized from mixtures of micron-sized boron and metal powders as a precursor [64-70]. Since the nucleation temperature of vapor was dependent on them [65], the ratio of boron to metal and the feeding rate were adjusted to control the size of the metal boride nanoparticles. The formation mechanism of various metal boride nanoparticles in the high thermal plasma flame has been discussed when analyzing nucleation temperatures and the thermal history inside the reactor. The formation mechanism of 

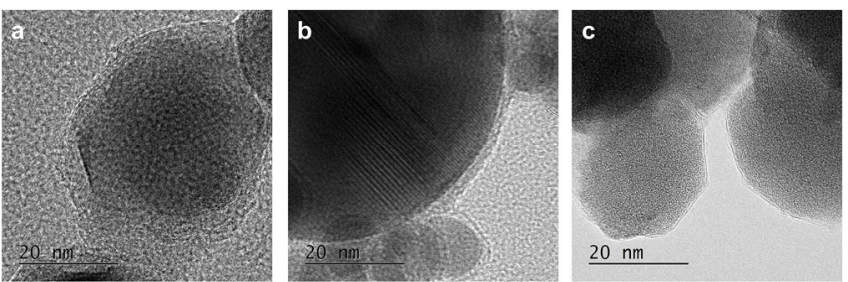

Figure 3. FE-TEM images of the synthesized nanoparticles formed using triple direct current thermal plasma system: (a) titanium borides, (b) nickel borides, and (c) tungsten borides.

metal boride nanoparticles in the thermal plasma flow subjected to rapid quenching is as follows. The injected precursor is first evaporated in the high temperature region of the thermal plasma jet. At that moment, when the vaporization temperature of boron is higher than the metal, the boron vapor nucleates first as it travels to the lower temperature region due to the lower saturation vapor pressure compared to the metal (except for niobium). Boron droplets stay in a molten state until the temperature reaches their solidification limit around 2,500 $\mathrm{K}$, and boridation then occurs with the metal monomer by co-condensation and coagulation during quenching. The nucleation temperatures of the boron and metal precursors were calculated according to the feeding rate and mixing ratio of the boron/metal. The nucleation temperature of boron was higher than for most metals. In addition, it was found that a high feed rate of boron precursor in a higher boron fraction in a particle with a larger crystalline diameter. This is caused by the elevated boron nucleation temperature which raises the vapor density and extends the temperature gap between the nucleation and solidification temperatures of the boron. Thus, particles grew through co-condensation and coagulation for a longer period.

Recently, a triple DC thermal plasma $\left(30 \mathrm{~kW}, 101 \mathrm{kPa}, \mathrm{Ar} / \mathrm{N}_{2}\right.$ plasma) was applied to synthesize titanium, nickel, and tungsten boride nanoparticles from micron-sized $\mathrm{Ti}, \mathrm{Ni}, \mathrm{W}$, and $\mathrm{B}$ powder, respectively, as shown in Fig. 3 [71]. Its advantages include a low operating cost, a simple system, and high thermal efficiency. Despite the higher vaporization temperature of tungsten, the synthesized tungsten boride nanoparticles were characterized by higher crystallinity than nickel boride nanoparticles. Because the tungsten vapor has a higher vaporization temperature than boron, it was nucleated first at the high temperature and the growth time of the co-condensation with boron was much longer than for nickel and boron. As a result, the high nucleation temperature influences the synthesization time of synthesized borides and crystalline structures.

\section{Conclusion}

Since the beginning of the $20^{\text {th }}$ century, many nanomaterials have been produced by thermal plasma. The scientific and technical effort to improve and commercialize thermal plasma synthetic processes and products has been accelerating rapidly since the 2000s. The technology behind thermal plasma synthesis is changing continuously. Ceramic nanomaterials were preferred over single metal nanomaterials for use in the high enthalpy environments of thermal plasma jets due to the Gibbs free energy phenomena. Nitride and carbide nanomaterials were widely synthesized as the use of microelectronics grew. Boride nanomaterials have high potential and have been the focus of many studies in recent years. Various composite nanoparticles or low-dimensional nanomaterials are needed to improve the performance and reduce the processing cost. However, the commercialization of thermal plasma synthetic processing of nanomaterials presents many challenges.. The advantages of thermal plasma synthesis, such as high enthalpy flows combined with a rapid quenching rate, are very promising; however, the formation process needs to be better understood. Diagnostic and numerical simulation of the nucleation and growth processes are needed to enable a better understanding of the rapid and extremely high temperature process detail of each stage. The important parameters must be determined to reliably control the quality and characteristics of the nanomaterials produced. Furthermore, the nanomaterials produced and synthesized need to be evaluated in terms of the performance of the nanomaterials in practical applications.

\section{Acknowledgement}

This research was supported by the 2019 scientific promotion program funded by Jeju National University.

\section{References}

[1] M. I. Boulos, P. Fauchais, and E. Pfender, Thermal Plasmas Fundamentals And Applications Volume 1, (1994).

[2] M. I. Boulos, IEEE Trans. Plasma Sci. 19, 1078 (1991).

[3] P. Fauchais, A. Vardelle, and A. Denoirjean, Surf. Coatings Technol. 97, 66 (1997).

[4] E. Pfender, Plasma Chem. Plasma Process. 19, 1 (1999).

[5] P. R. Taylor and S. A. Pirzada, Adv. Perform. Mater. 1, 35 (1994).

[6] J. S. Oh and G. Y. Yeom, Appl. Sci. Converg. Technol. 26, 149 (2017).

[7] M. Y. Hur, D. Lee, S. Yang, and H. J. Lee, Appl. Sci. Converg. Technol. 27, 14 (2018).

[8] S. Bae, S. K. Lee, and M. Park, Appl. Sci. Converg. Technol. 27, 79 (2018).

[9] G. Jiayin, F. Xiaobao, R. Dolbec, X. Siwen, J. Jurewicz, and M. Boulos, Plasma Sci. Technol. 12, 188 (2010).

[10] J. Seo and B. Hong, Nucl. Eng. Technol. 44, 9 (2012).

[11] K. Zaharieva, G. Vissokov, J. Grabis, and S. Rakovsky, Plasma Sci. Technol. 14, 980 (2012).

[12] S. Samal, J. Clean. Prod. 142, 3131 (2017).

[13] Y. Chang and E. Pfender, Plasma Chem. Plasma Process. 7, 275 (1987).

[14] Y. Chang, R. M. Young, and E. Pfender, Plasma Chem. Plasma Process. 7, 299 (1987).

[15] Y. C. Lee and E. Pfender, Plasma Chem. Plasma Process. 7, 1 (1987).

[16] T. H. Kim, S. Choi, and D. W. Park, J. Korean Phys. Soc. 63, 1864 (2013).

[17] S. J. Lee, T. H. Kim, D. W. Kim, and D. W. Park, Plasma Chem. Plasma Process. 37, 967 (2017).

[18] T. H. Kim, H. G. Jeong, and D. W. Park, Sci. Adv. Mater. 9, 1637 (2017).

[19] T. H. Kim, D. W. Park, and S. Choi, J. Korean Phys. Soc. 66, 1233 (2015).

[20] K. S. Kim, M. J. Kim, C. Park, C. C. Fay, S. H. Chu, C. T. Kingston, and B. Simard, Semicond. Sci. Technol. 32, 013003 (2016). 
[21] K. S. Kim, M. Imris, A. Shahverdi, Y. Alinejad, and G. Soucy, J. Phys. Chem. C 113, 4340 (2009).

[22] K. S. Kim and T. H. Kim, J. Appl. Phys. 125, 070901 (2019).

[23] K. Kawajiri and H. Nishiyama, Thin Solid Films 506, 660 (2006).

[24] K. S. Kim, J. H. Seo, J. S. Nam, W. T. Ju, and S. H. Hong, IEEE Trans. Plasma Sci. 33, 813 (2005).

[25] H. Takana, J. Jang, J. Igawa, T. Nakajima, O. P. Solonenko, and H. Nishiyama, J. Therm. Spray Technol. 20, 432 (2011).

[26] M. K. Mun, W. O. Lee, J. W. Park, D. S. Kim, G. Y. Yeom, and D. W. Kim, Appl. Sci. Converg. Technol. 26, 164 (2017).

[27] M. Shigeta and A. B. Murphy, J. Phys. D. Appl. Phys. 44, 174025 (2011)

[28] S. M. Oh and T. Ishigaki, Thin Solid Films 457, 186 (2004).

[29] J. G. Li, M. Ikeda, R. Ye, Y. Moriyoshi, and T. Ishigaki, J. Phys. D. Appl. Phys. 40, 2348 (2007).

[30] Y. L. Li and T. Ishigaki, J. Phys. Chem. B 108, 15536 (2004).

[31] C. Y. Tsai, H. C. Hsi, T. H. Kuo, Y. M. Chang, and J. H. Liou, Aerosol Air Qual. Res. 13, 639 (2012).

[32] J. W. Park, D. W. Kim, H. S. Seon, K. S. Kim, and D. W. Park, Thin Solid Films 518, 4113 (2010).

[33] J. E. Lee, S. M. Oh, and D. W. Park, Thin Solid Films 457, 230 (2004).

[34] C. Y. Tsai, H. C. Hsi, H. Bai, K. S. Fan, and H. D. Sun, Jpn. J. Appl. Phys. 51, 1 (2012).

[35] G. Hou, B. Cheng, F. Ding, M. Yao, P. Hu, and F. Yuan, ACS Appl. Mater. Interfaces 7, 2873 (2015).

[36] S. M. Oh and D. W. Park, Thin Solid Films 316, 189 (1998).

[37] C. U. Bang, Y. C. Hong, and H. S. Uhm, Surf. Coatings Technol. 201, 5007 (2007).

[38] F. Allarie and S. Dallaire, J. Mater. Sci. 26, 6736 (1991).

[39] T. H. Kim, S. Choi, and D. W. Park, Nanomaterials 6, 1 (2016).

[40] T. H. Kim, E. H. Ko, J. Nam, S. E. Shim, and D. W. Park, J. Nanosci. Nanotechnol. 17, 9217 (2017).

[41] K. S. Kim, M. Couillard, H. Shin, M. Plunkett, D. Ruth, C. T. Kingston, and B. Simard, ACS Nano 12, 884 (2018).

[42] K. S. Kim, C. T. Kingston, A. Hrdina, M. B. Jakubinek, J. Guan, M. Plunkett, and B. Simard, ACS Nano 8, 6211 (2014).

[43] X. Blase, A. Rubio, S. G. Louie, and M. L. Cohen, Europhys. Lett. 28, 335 (1994).

[44] K. S. Kim, M. B. Jakubinek, Y. Martinez-Rubi, B. Ashrafi, J. Guan, K. O’Neill, M. Plunkett, A. Hrdina, S. Lin, S. Dénommée, C. Kingston, and B. Simard, RSC Adv. 5, 41186 (2015).

[45] W. Q. Han, W. Mickelson, J. Cumings, and A. Zettl, Appl. Phys. Lett. 81, 1110 (2002).

[46] D. Golberg, Y. Bando, C. Tang, and C. Zhi, Adv. Mater. 19, 2413 (2007).

[47] D. Golberg, Y. Bando, Y. Huang, T. Terao, M. Mitome, C. Tang, and C. Zhi, ACS Nano 4, 2979 (2010).

[48] A. Fathalizadeh, T. Pham, W. Mickelson, and A. Zettl, Nano Lett.
14,4881 (2014).

[49] M. Kim, Y. H. Lee, J. H. Oh, S. H. Hong, B. I. Min, T. H. Kim, and S. Choi, Chem. Eng. J. 395, 125148 (2020).

[50] E. H. Ko, T. H. Kim, S. Choi, and D. W. Park, J. Nanosci. Nanotechnol. 15, 8515 (2015).

[51] D. W. Kim, T. H. Kim, H. W. Park, and D. W. Park, Appl. Surf. Sci. 257, 5375 (2011).

[52] A. V. Samokhin, V. A. Sinaiskii, N. V. Alekseev, E. V. Troitskaya, and Y. V. Tsvetkov, Inorg. Mater. Appl. Res. 5, 224 (2014).

[53] M. Kakati, B. Bora, S. Sarma, B. J. Saikia, T. Shripathi, U. Deshpande, A. Dubey, G. Ghosh, and A. K. Das, Vacuum 82, 833 (2008).

[54] S. M. Oh, M. Cappelli, and D. W. Park, Korean J. Chem. Eng. 19, 903 (2002).

[55] T. Ryu, H. Y. Sohn, K. S. Hwang, and Z. Z. Fang, J. Mater. Sci. 43, 5185 (2008).

[56] T. Ryu, H. Y. Sohn, K. S. Hwang, and Z. Z. Fang, J. Am. Ceram. Soc. 92, 655 (2009).

[57] A. V. Samokhin, N. V. Alekseev, S. A. Kornev, M. A. Sinaiskii, Y. V. Blagoveschenskiy, and A. V. Kolesnikov, Plasma Chem. Plasma Process. 33, 605 (2013).

[58] P. V. Krasovskii, O. S. Malinovskaya, A. V. Samokhin, Y. V. Blagoveshchenskiy, V. A. Kazakov, and A. A. Ashmarin, Appl. Surf. Sci. 339, 46 (2015).

[59] J. H. Oh, M. Kim, Y. H. Lee, S. H. Hong, T. H. Kim, and S. Choi, J. Nanosci. Nanotechnol. 19, 6277 (2019).

[60] L. Tong and R. G. Reddy, Scr. Mater. 52, 1253 (2005).

[61] T. Ishigaki, S. M. Oh, J. G. Li, and D. W. Park, Sci. Technol. Adv. Mater. 6, 111 (2005).

[62] J. P. Scheifers, Y. Zhang, and B. P. T. Fokwa, Acc. Chem. Res. 50, 2317 (2017).

[63] H. R. Baumgartner and R. A. Steiger, J. Am. Ceram. Soc. 67, 207 (1984).

[64] Y. Cheng, M. Shigeta, S. Choi, and T. Watanabe, Chem. Eng. J. 183,483 (2012).

[65] Y. Cheng, S. Choi, and T. Watanabe, Powder Technol. 246, 210 (2013).

[66] T. Watanabe, A. Nezu, Y. Abe, Y. Ishii, and K. Adachi, Thin Solid Films 435, 27 (2003).

[67] M. Shigeta and T. Watanabe, Thin Solid Films 515, 4217 (2007).

[68] Y. Cheng, S. Choi, and T. Watanabe, J. Phys. Conf. Ser. 441, 012031 (2013).

[69] S. Choi, L. D. S. Lapitan, Y. Cheng, and T. Watanabe, Adv. Powder Technol. 25, 365 (2014).

[70] Y. Cheng, M. Tanaka, T. Watanabe, S. Y. Choi, M. S. Shin, and K. H. Lee, J. Phys. Conf. Ser. 518, 012026 (2014).

[71] M. Kim, J. H. Oh, T. H. Kim, Y. H. Lee, S. H. Hong, and S. Choi, J. Nanosci. Nanotechnol. 19, 6264 (2019). 